\title{
Editorial
}

Articles for the third issue of the Journal of Business Systems, Governance and Ethics again span a wide range of business-related research issues that reflect the interests of academic staff and doctoral students at Victoria University. This issue has articles relating to sociology, ethics, information systems, economics and corporate governance. As with previous issues these articles cover issues in both Australia and Asia.

In the first article: The Coffee House Conversations - Socio-Technical Turtles all the Way Down, Andrew Wenn makes use of dialogue and photographs to explore the socio-technical nature of the apparently straightforward act of providing parking spaces for cars, and shows that this is in fact anything but straightforward. Wenn's analysis reveals that a wide variety of social and technical artefacts including batteries, clocks, computers, data, economics, engineering compromises, gatekeepers, humans, politics, procedures and standards configured into a complex network, must be taken into consideration when trying to understand this process. He ends by developing a simple graphical metaphor that enables us to better understand the heterogeneous nature of such structures.

A study by Wusheng Zhang and Mik Kim in an article entitled: What Works and What Does Not - an Analysis of Application Frameworks Technology, suggests that application frameworks technology does support large-scale reuse by incorporating other existing reuse techniques such as design patterns, class libraries and components, but that the methodological support for building and implementing application frameworks is inadequate. Their study indicates that application frameworks technology may increase the quality of software in terms of correctness and reusability, but that there is no guarantee of increasing the extendability and interoperability of software systems.

An article by James Doughney: The No 'Ought' From 'Is' Argument - Faulty Thinking in Ethics and Social Science, explores why the dichotomies engendered by the 'positivist' approach - fact/value, positive/normative and descriptive/evaluative - are false. The main reason, the paper argues, is that the fundamental principle underlying the approach fails. This principle, the 'no ought from is argument', is the formally structured argument that a value (ought) cannot logically be derived from a fact (is). The paper rejects this argument and, especially, its iconic status in economics.

Xinting Jia next makes an international comparison of Corporate Governance in State Controlled Enterprises, focusing on corporate governance in Telstra in Australia and China Telecom in China. By comparing and contrasting corporate governance in these two companies the article explores practices and mechanisms in partially listed state controlled enterprises under the dramatically different socioeconomic environments manifested by these two countries.

In the final article, Three Questions to Guide Study and Practice in the Information Systems Field, JuanQiong Gou from Beijing Jiaotong University and I investigate the various influences on MIS curriculum and some of the conventional approaches to curriculum design, selection and organisation of teaching materials. The paper then offers an alternative approach by presenting a three question framework for understanding and explaining the IS field, and argues that these three questions can be used to guide the study, teaching and practice of MIS.

All papers in the journal have been subjected to a process of blind peer review by at least two reviewers. Articles were then only accepted after appropriate changes and corrections had been made by the authors. We hope that you find the content of this issue both interesting and readable.

\section{Arthur Tatnall}

Editor 
